\title{
Apropriação dos conceitos de Lev Semenovitch Vigotski no âmbito das pesquisas em Educação Física
}

\author{
Taiza Daniela Seron* \\ Ieda Parra Barbosa-Rinaldi** \\ Silvana Calvo Tuleski***
}

\begin{abstract}
Resumo: Investiga como se deu a apropriação dos conceitos de Vigotski em trabalhos científicos publicados na área da educação física entre os anos de 1990 a 2007, no sentido de verificar quais conceitos foram utilizados e de que forma foram incorporados. Seleciona, para o estudo, três revistas da área: Revista Brasileira de Ciências do Esporte, Movimento e Revista da Educação Física/UEM. O trabalho é bibliográfico e a metodologia de análise é o materialismo histórico-dialético. Os resultados apontaram que é preciso avançar nos estudos sobre Vigotski, no sentido de potencializar pesquisas acadêmicas de maior rigor epistemológico.
\end{abstract}

Palavras-chave: Psicologia Histórico-Cultural. Epistemologia. Pesquisas. Educação Física.

\section{INTRODUÇÃo}

No final da década de 1980 o quadro educacional brasileiro passou por diversas mudanças motivadas por vários referenciais teóricos que buscavam a melhoria da prática pedagógica trazendo novas ideias para a área. Entre esses referenciais estavam os de Vigotski ${ }^{1}$. Algumas de suas obras, traduzidas para o português foram muito utilizadas: Formação Social da Mente, em 1984, Pensamento e Linguagem, em 1987, e Linguagem, Desenvolvimento e Aprendizagem, em 1988 (SILVA, 2003).

\footnotetext{
*Universidade Estadual de Maringá. Maringá, PR, Brasil. E-mail: taizaseron@hotmail.com **Universidade Estadual de Maringá. Maringá, PR, Brasil. E-mail: parrarinaldi@hotmail.com ***Universidade Estadual de Maringá. Maringá, PR, Brasil. E-mail: sctuleski@uem.br 'Lev Semenovitch Vigotski: psicólogo russo, um dos representantes da Teoria Histórico-Cultural. O nome de Vigotski foi grafado de diferentes maneiras, contudo utilizaremos no decorrer do texto a grafia "Vigotski" e preservaremos as que forem utilizadas de forma diferente nas obras citadas.
} 
Contudo, algumas dessas obras não apresentavam uma tradução fidedigna, isso porque algumas, como Formação Social da Mente (1989) e Pensamento e Linguagem (1989), tiveram ideias retiradas, principalmente no que tange à fundamentação em Marx, Lênin e Trotsky e trechos acrescentados, de acordo com o entendimento do tradutor. Duarte (2001, p. 170) destaca que essas modificações devem ter "[...] facilitado a aceitação do livro de Vigotski, posto que tornaram o texto mais facilmente interpretável à luz de concepções nãomarxistas do ser humano, da história e das relações entre indivíduo e sociedade".

Em virtude desses acontecimentos, os conceitos vigotskianos foram perdendo sua essência e sua historicidade levando diferentes áreas (psicologia, educação, educação física) a se apropriarem de modo simplificado e distorcido da Psicologia Histórico-Cultural, passando a empregá-los de forma equivocada, tanto na área acadêmica como em sua prática pedagógica.

Na década de 1990 as ideias de Vigotski foram amplamente divulgadas em pesquisas na área da Psicologia e da Educação, e segundo Silva (2003, p. 4), com o interesse crescente pelas ideias vigotskianas, outras obras foram traduzidas para o português, tais como:

"Teoria e Método em Psicologia", em 1996; "A História do Comportamento: o macaco, o primitivo e a criança", em 1996; "O Desenvolvimento Psicológico na Infância" em 1998; "Hamlet, o príncipe da Dinamarca", em 1999; "Psicologia da Arte", em 1999; "Psicologia Pedagógica", em 2001; "A Imaginação e a Arte na Infância", ainda de tradução espanhola além das "Obras Escogidas", também em espanhol, composta de seis tomos (Tomo I em 1991; Tomo II em 1993; Tomo III em 1995; Tomo IV em 1996; Tomo V em 1997 e Tomo VI, em 2002, com tradução para o inglês.

Foi somente a partir do ano de 2000 que algumas obras foram traduzidas diretamente do original em russo, como é o caso da obra A Construção do Pensamento e da Linguagem. No entanto, 
percebemos que mesmo após o aparecimento dessas obras completas, as pesquisas ainda utilizavam o referencial cuja tradução não apresentava os fundamentos filosóficos da psicologia vigotskiana, gerando equívocos conceituais, refletindo o descuito com as fontes e a superficialidade de muitas pesquisas na área acadêmica (DUARTE, 2001; FACCI, 2004).

Perante esse quadro, estabelecemos como objetivo dessa pesquisa investigar como se deu a apropriação dos conceitos de Vigotski em trabalhos científicos publicados na área da Educação Física entre os anos de 1990 a 2007, no sentido de verificar quais conceitos foram utilizados e de que forma foram incorporados.

Para esse estudo utilizamos o método de pesquisa bibliográfico, que segundo Trujillo Ferrari (1982, p. 209) tem por finalidade "[...] conhecer as contribuições científicas que se efetuaram sobre determinado assunto" ou mapear o "estado da arte" em relação a um determinado tema. A metodologia de análise foi a análise conceitual, objetivando revelar a maneira que vem se dando as apropriações da Psicologia Histórico-Cultural nas pesquisas no âmbito da Educação Física. Sobre o assunto, Saviani (2004) ressalta que, a reflexão torna-se filosófica quando a problematização é reflexionada a partir de três categorias: a radicalidade (ir às raízes da questão), o rigor (sistematizar por métodos determinados) e a globalidade (examinar o problema a partir da perspectiva de conjunto, relacionando com todos os aspectos do contexto no qual está inserido).

Selecionamos como fontes de análise, artigos que mencionaram nas referências bibliográficas obras de Vigotski, e que foram publicados entre os anos de 1990 a 2007 em três periódicos da área: Movimento; Revista da Educação Física da UEM/PR e Revista Brasileira de Ciências do Esporte (RBCE). A seleção destas revistas deu-se em virtude das mesmas terem circulação em âmbito nacional e por serem reconhecidas pela qualidade de seus artigos, conforme avaliação feita pelo sistema Qualis/CAPES ${ }^{2}$.

${ }^{2}$ CAPES: Coordenação de Aperfeiçoamento de Pessoal de Nível Superior.

Movimento, Porto Alegre, v. 17, n. 02, p. 75-91, abr/jun de 2011. 
Consideramos que a presente pesquisa é de interesse de estudiosos da área da educação e da Educação Física, que se dedicam ao estudo da Psicologia Histórico-Cultural e se apropriam das ideias de Vigotski em seus estudos e sua prática pedagógica. Além disso, traz análise significativa do trato dos fundamentos vigotskianos na área, destacando como os mesmos foram apropriados. Acreditamos que, com esse estudo poderemos contribuir com a divulgação das ideias da Psicologia Histórico-Cultural no âmbito acadêmico da Educação Física, em especial no que tange às obras de Vigotski, bem como esclarecer pontos cruciais presentes na psicologia soviética.

\section{VIGOTSKI NO BRASIL: IDEIAS E CONCEITOS APROPRIADOS}

Vigotski viveu na Rússia durante a Revolução de 1917 e sentiu as consequências da desintegração das classes sociais e do capitalismo. Tuleski (2002, p. 54) destaca que nos anos seguintes à revolução socialista não é possível afirmar que o aspecto da sociedade soviética correspondesse à essência do projeto coletivo que a impulsionou, pois mesmo a abolição jurídica da propriedade privada não garantia a eliminação das relações burguesas. "Esta contradição, intrinsecamente ligada à luta de classes no interior da Rússia e ao período de reconstrução da sociedade, que ora imprimia características burguesas, ora socialistas, às relações de produção, será o fio condutor para a análise da psicologia Vygotskiana". Este meio social foi decisivo para que Vigotski elaborasse sua teoria. A autora ainda afirma que em suas obras Vigotski buscou:

[.... superar a 'velha psicologia', postulando uma 'nova psicologia' que fosse capaz de eliminar a dicotomia entre corpo e mente e realizar a síntese. Esta dicotomia foi historicamente o pomo da discórdia entre as teorias psicológicas, justificando sua classificação entre idealistas e materialistas. Vygotski parece perseguir o objetivo de superá-la, trazendo para a psicologia o método proposto por Marx e Engels e construindo a ponte que eliminaria a cisão entre a matéria e o espírito (TULESKI, 2002, p. 55). 
Entretanto, suas obras foram sendo apropriadas em diversas partes do mundo e aquilo que representa o centro de suas discussões - materialismo histórico-dialético - foi em muitos casos retirado e por outros, desconsiderado.

Outro aspecto destacado por Duarte (2001, p. 161) é que os nomes de Luria e Leontiev ${ }^{3}$ são rapidamente citados nos estudos ${ }^{4}$ sobre Vigotski e logo são deixados de lado, objetivando "[...] neutralizar o caráter marxista da teoria vigotskiana e com isso facilitar a assimilação do pensamento de Vigotski ao universo ideológico próprio ao capitalismo contemporâneo". O autor também observa que no Brasil inúmeros livros trazem Vigotski em seu título, no entanto, sem o cuidado necessário em preservar a base teórica da psicologia vigotskiana, um exemplo disso é a tradução do livro Pensamento e Linguagem (1993) "[...] cuja primeira edição brasileira foi lançada em 1987, não é tradução do texto original, mas sim de uma versão resumida publicada em inglês, nos EUA, em 1962. Essa versão resumida cortou mais de 60\% do texto original", (DUARTE, 2001, p. 161) sendo que o texto original publicado na obra Obras Escolhidas em espanhol possui 337 páginas enquanto que a edição em português apresenta apenas 137 páginas, "[...] tornando assim, o pensamento de Vigotski mais soft, menos marxista e mais facilmente adaptável ao pragmatismo norte-americano" (DUARTE, 2001, p. 168).

Outro problema apontado é em relação ao ecletismo nas interpretações da teoria vigotskiana, muitos autores aproximam as teorias de Vigotski e Piaget, ao reconhecer a vasta contribuição de ambos para a área da educação, acreditando que haja afinidades essenciais entre suas abordagens. Sobre o assunto, Duarte (2001, p. 177) destaca a defesa de César Coll no campo do currículo escolar, da "[...] adoção de um marco referencial construtivista, constituído pela justaposição de idéias retiradas de várias teorias psicológicas, entre elas as de Vigotski e Piaget".

\footnotetext{
${ }^{3}$ Alexander Romanovich Luria e Alexei Nikolaevich Leontiev: psicólogos russos que, juntamente com Vigotski, contribuíram para a formulação da Teoria Histórico-Cultural.

${ }^{4}$ Para detalhes sobre os estudos citados consultar a obra de Duarte (2001).
} 
Entre os problemas gerados por esta prática, este pragmatismo se estende aos setores das pesquisas em psicologia e psicologia educacional, exigindo dos pesquisadores pesquisas rápidas e imediatas para problemas imediatos. Sobre o assunto, Moraes (2001, p. 10-11) salienta a ansiedade dos programas de pós-graduação brasileiros, que obrigados a atender uma demanda do sistema de avaliação e acompanhamento (CAPES), aceleram seus prazos de conclusão de mestrado e doutorado, sem contar as ameaças de perda de bolsas-de-estudo dos alunos.

Esse processo de aceleração do processo de formação na pósgraduação pode levar ao que Duarte (2001, p. 178) apresenta como equívoco, que é o enquadramento de Vigotski e Piaget como interacionistas, "[...] a aproximação é favorecida mesmo quando os autores se esforcem por estabelecer distinções entre as duas teorias adjetivando a de Vigotski como sociointeracionista".

Este quadro revela o longo caminho que é necessário percorrer para conhecer as ideias de Vigotski, haja vista que distorções de suas obras, como as que citamos acima, põem em xeque sua raiz filosófica, sua essência e sua história. Por outro lado, quando descobertos, esses materiais ilegítimos, vão perdendo sua força e validade no cenário educacional, constituindo um passo de superação e de oportunidade de revelar as teses vigotskianas.

\section{ANÁLISE DA APROPRIAÇÃO DOS CONCEITOS DE VIGOTSKI NA ÁREA DA EducaÇÃo FísICA}

Em quase 20 anos da divulgação das ideias de Vigotski no Brasil, na área da educação física foram poucos os estudos que tomaram por base o referencial soviético. Dentre 822 artigos pesquisados, apenas 35 utilizaram o autor, representando uma parcela de 4,3\%. Destes, a maioria estava presente na Revista Brasileira de Ciência do Esporte (RBCE) $(n=18)$, representando 51,4\% dos artigos.

Pudemos notar que entre os anos de 2000 a 2007, a publicação de artigos, tendo Vigotski como referência, teve aumento considerável 
de 42,9\%. No período que compreende os anos de 1990 a 1999 foram 14 artigos encontrados, e de 2000 a 2007 este número aumentou para 20. Entendemos que, dentre outros motivos, este fato pode ser justificado pelo já mencionado, a formação aligeirada e acelerada exigida dos programas de pós-graduação.

A partir do quadro estabelecido, nos questionamos se o aumento dos estudos tomando como base a teoria vigotskiana caminhou lado a lado com a utilização das obras que trazem toda a base filosófica da teoria de Vigotski, aquelas traduzidas após o ano de 2000. E, verificamos que a partir do que foi analisado, a obra mais citada foi Formação Social da Mente, com 44,34\% das citações, variando nos anos de edição: 1982, 1984, 1987, 1988, 1989, 1991, 1994, 1998 e 2002, seguida da obra Pensamento e Linguagem com 16,3\%. Sobre estas obras, Duarte (2001, p. 168) afirma que não foram traduzidas na íntegra, a tradução tinha o objetivo de "[...] descaracterizar a conotação fortemente crítica do texto de Vigotski em relação não só ao pensamento de Piaget como também ao idealismo presente em boa parte das teorias psicológicas, tornando, assim, o pensamento de Vigotski mais soft, menos marxista e mais facilmente adaptável".

Em busca da compreensão e da simplificação, palavras, significados e o próprio contexto histórico de Vigotski foram deixados de lado. Duarte (2001, p. 170) salienta que "[...] somos obrigados a admitir que as alterações feitas devem ter, realmente, facilitado a aceitação do livro de Vigotski, posto que tornaram o texto mais facilmente interpretável à luz das concepções não-marxistas do ser humano e das relações entre indivíduo e sociedade".

Além dessas obras ainda apareceram: Linguagem, desenvolvimento e aprendizagem (1988, 1991), Obras Escogidas (1997), Thought and Language (1962), Estudos sobre a história do comportamento: macaco, o primitivo e a criança (1996) e Obras completas/fundamentos de defectologia (1989).

De acordo com Tuleski (2008) as obras que mais se mantiveram fiéis ao original russo foram as traduções espanholas: Fundamentos de defectologia (1989), Problemas teóricos y metodológicos de la 
psicología (1991), Problemas de psicología general (1993) e Problemas del desarrollo de la psique (1995). Em nossas incursões nos artigos pesquisados, pudemos perceber que a maioria dessas obras apontadas acima não é citada nas referências dos artigos analisados, salvo Obras Escogidas (1997). Este fato nos leva a refletir sobre a autenticidade dos textos que se tornam referência para os estudos pesquisados. E mais, sobre o tipo de produção científica que vem sendo configurada no contexto acadêmico da área da educação física. Além disso, poucos autores tomaram como base a nova edição de Pensamento e Linguagem, publicada com o título A Construção do Pensamento e da Linguagem, a partir de 2000, cuja tradução foi realizada diretamente do original em russo.

Quanto aos conceitos vigotskianos, os que se referiam ao entendimento da atividade motora, das brincadeiras e jogos na infância somou 21,4\% das citações. Notamos que os autores basearam-se em Vigotski para defender a presença dos jogos e brincadeiras infantis na vida das crianças, e também na escola. Com $12,5 \%$ apareceu o conceito de zona de desenvolvimento proximal. Os outros $66,1 \%$ dos conceitos se referiam a questões da linguagem, e sua relação com a leitura e a escrita, as funções psicológicas superiores, o meio social, os conhecimentos espontâneos e científicos, a conciência, a educação inclusiva e aspectos ligados à escola e ao professor. Dentre esses conceitos, foram encontrados alguns equívocos de interpretação.

Goellner (1992) abordou o desenvolvimento do homem a partir de um prisma histórico-dialético, destacando as contribuições de Vigotski, Luria e Leontiev, para o entendimento do homem social. Contudo, o conceito de zona de desenvolvimento proximal é abordado de maneira equivocada em alguns aspectos, pois para a autora:

[...] o nível real de desenvolvimento diz respeito ao que a criança já pode agir de forma autônoma e independente e o nível de desenvolvimento potencial refere-se às funções psicológicas que está começando a desenvolver e dominar, a zona de desenvolvimento proximal situa-se então entre esses dois níveis é a na zona de desenvolvimento potencial 
que a criança ainda necessita de orientação de adultos e de seus companheiros (GOLLNER, 1992, p. 291).

Outros autores também apresentam três zonas de desenvolvimento, quando abordam sobre a zona de desenvolvimento proximal. Entre os equívocos estão os trabalhos de Castro Júnior e Sant'anna Sobrinho (2002), Falkenbach, Drexsler e Werle (2007, p. 109) e mais uma vez Falkenbach (2003). Para ele:

Vygotsky (1991) destaca dois níveis de desenvolvimento: o real e o potencial. O primeiro é o que a criança já sabe por si mesma, sem o auxílio do outro, enquanto o segundo diz respeito ao que a criança pode vir a ser capaz de fazer. Na distância entre a zona real e a zona potencial, está a zona de desenvolvimento proximal. Esta última, são todas as formas de auxílio externo que possibilitam despertar as aprendizagens que ainda não são possíveis sem ajuda, orientação, modelos, entre outras diversas formas de auxílio externo (FALKENBACH, 2003, p. 116, grifo nosso).

Em todos os trabalhos citados acima, os autores acrescentam uma terceira zona de desenvolvimento. Vale destacar que zona de desenvolvimento potencial e proximal trata-se do mesmo conceito, o que ocorre é que devido às traduções "editadas" das obras de Vigotski, que chegaram ao Brasil na década de 1990, como demonstrado por Duarte (2001), contriburam para a má interpretação do autor.

Percebemos também que a referência ao meio social foi mal interpretada e por vezes simplificada, relegando-a simplesmente às relações cotidianas com os pais, a família ou os professores. Nem sempre os autores traziam Vigotski, mas nas discussões ficava implícita tal situação, o que é possível compreender melhor com a análise dos textos. Quanto aos outros conceitos não observamos grandes problemas conceituais, mas com as formas de utilização desses conceitos, mesmo fidedignos à psicologia soviética deixava a desejar. 
Notamos que, $60 \%$ dos artigos consultados apropriam-se de Vigotski complementando-o com outros autores. Entre esses autores podemos citar: Piaget, Bronfenbrenner, Kant, Winnicott, Wallon, Leontiev, Benjamin, Borges, Freire, Fernandes, Negrine, entre outros. Notamos que muitas dessas complementações buscavam aproximar as ideias de Vigotski a discursos diferentes do que realmente o que ele defende, excetuando Leontiev que é um dos fundadores da Psicologia Histórico-Cultural.

Cerca de $20 \%$ dos artigos mencionaram Vigotski apenas de passagem, ou seja, isoladamente sem contextualização; 8,6\% compararam as ideias vigotskianas a outros autores, confrontandoas e apresentado diferenças; $8,6 \%$ apresentaram o autor somente nas referências do texto, não constituindo base para as discussões do artigo e; somente $2,9 \%$ estavam fundamentados, traziam as ideias vigotskianas a partir da Psicologia Histórico-Cultural.

Duarte (1995) enfatiza que, para termos uma leitura pedagógica dos trabalhos da Escola de Vigotski, compreendendo e entendendo o significado de seus conceitos, temos que atentar para quatro hipóteses fundamentais: primeira, é imprescindível o estudo dos fundamentos filosóficos marxistas incorporados por esta escola psicológica; segunda, estudar sua obra como parte de um conjunto de trabalhos elaborados pela Psicologia Histórico-Cultural; terceira, sua escola não é interacionista, nem construtivista; e quarta, uma leitura pedagógica escolanovista se contrapõe aos princípios pedagógicos dessa escola psicológica.

Apoiado em bases marxistas e no método do materialismo histórico-dialético, Vigotski, e seus seguidores (Luria e Leontiev, além de Elkonin, Galperin, Davidov, Zaporózhets, entre outros) propuseram uma teoria que não negou a influência social, cultural e histórica na formação da mente do homem e na determinação das relações do homem com seus semelhantes e bem como, com a natureza. Esta teoria, denominada Histórico-Cultural, trouxe à luz da psicologia uma nova forma de entender o homem. Esta base filosófica, negada em diversas obras, dão o aporte fundamental para o entendimento da psique a partir do método de Marx (TULESKI, 2002). 
Para os estudiosos marxistas, o tipo psicológico do homem moderno é fruto de duas linhas de evolução: a biológica e a social, sendo que a primeira fica relegada a segunda com o início da vida social e histórica humana, a qual tem em suas raízes a determinação para a formação da psique humana. O homem ao deixar o primitivismo, tece novos tipos de relações sociais que modificam suas prioridades de sobrevivência e sua relação com os outros homens. Relações essas, agora, de produção, de trabalho, de classes, de interação social, o que pressupõe relações sociais de produção (DUARTE, 1995). E é a partir dessas relações que a criança apropriase de tudo o que a humanidade desenvolveu ao longo dos anos sem precisar passar por todas as descobertas e transformações acumuladas ao longo da história da humanidade

O desenvolvimento humano depende da intrínseca dependência do indivíduo das apropriações culturais mediadas pelos indivíduos mais desenvolvidos. E é nesta relação que entendemos o nível real e o potencial/proximal. De acordo com a Teoria de Vigotski esses dois níveis assim se constituem:

O primeiro nível é denominado de nível de desenvolvimento real ou efetivo, e costuma ser determinado pela solução individual do problema. Este nível constitui as funções psicológicas já efetivadas, formadas e amadurecidas pelo indivíduo, como resultado de certos ciclos de desenvolvimento já completados. O segundo nível de desenvolvimento é o desenvolvimento potencial, proximal ou próximo, definido como aquelas funções que estão em vias de amadurecer e que podem ser identificadas mediante a solução de tarefas, com o auxílio de adultos e outras crianças mais experientes. Enquanto aquele nível caracteriza o desenvolvimento mental retrospectivamente, este o caracteriza prospectivamente (ROMA et al., 2007 p. 89).

Aqui esclarecemos apropriações equivocadas deste conceito vigotskiano que foram encontradas nos textos analisados. Enfatizando que o Nível de desenvolvimento Potencial e a Zona de 
Desenvolvimento Proximal tratam do mesmo conceito, o que ocorreu é que as traduções das obras de Vigotski permitiram que estas imprecisões acontecessem. Duarte (1995, p. 23) confirma estes equívocos destacando que,

[...] o conceito de nível de desenvolvimento atual aparece em algumas traduções como nível de desenvolvimento real e em outras aparece ainda como nível de desenvolvimento efetivo. $\mathrm{O}$ conceito de zona de desenvolvimento próximo aparece em algumas traduções como zona de desenvolvimento proximal e em outras traduções como área de desenvolvimento potencial. Essas variações não são em si mesmas um problema. O problema é que existem intérpretes que entendem existirem em VIGOTSKI três conceitos ao invés de dois.

Para a área da defectologia, os pressupostos sobre o desenvolvimento real e potencial são os mesmos. Vigotski é muito utilizado para discutir a inclusão, principalmente a inclusão escolar. Porém, muitas vezes essa prática inclusiva fica reduzida a colocar (acumular sem responsabilidade) as crianças com deficiências na escola, sem que nenhum avanço para seu aprendizado realmente aconteça. Ao discutir sobre este tema, Vigotski aponta para a apropriação, por parte de todas as pessoas, de todo conhecimento produzido pela sociedade, incluir para esta perspectiva é dar as mesmas oportunidades a todos e não apenas fazer uma política de arranjo. Nesta perspectiva, de acordo com Duarte (2001) o impedimento do indivíduo à apropriação da riqueza material e intelectual, que foi produzida socialmente pelo homem, é a forma mais básica de alienação, ou seja, o processo de alienação impede que o homem aproprie-se da riqueza do gênero humano, impede sua humanização.

Entender a psicologia soviética é compreender que somente uma pedagogia crítica e historicizadora podem constituir um referencial de base para superar a alienação na sociedade capitalista, permitindo que a transformação aconteça. E para que possamos 
alcançar a tão desejada teoria crítica devemos nos apropriar da teoria vigotskiana, compreendida em seus fundamentos marxistas para que possa exercer seu papel revolucionário.

De acordo com Duarte (2001, p. 283) vemos que a psicologia de Vigotski pode constituir material de estudo para se construir uma pedagogia marxista, mas a mesma não pode produzir uma "pedagogia vigotskiana", "pretender criar uma "pedagogia vigotskiana seria incidir no psicologismo que entendemos ser incompatível com uma concepção marxista das relações entre indivíduo e sociedade". Além do mais, a construção de uma pedagogia marxista é decorrência da relação entre teoria e prática "como articulação entre a questão educacional e a questão política", com vistas na superação das relações capitalistas a partir de um projeto político socialista.

Contudo, vale ressaltar que esta construção não é simples assim, já que, de acordo com Moraes (2001), nas pesquisas educacionais atuais as discussões teóricas estão sendo cada vez mais suprimidas, ao mesmo tempo em que se gera a ideia incoerente de que a educação pode ser o remédio para todos os males que permeiam a sociedade, a partir de uma educação voltada às competências. A autora aponta para políticas educacionais nacionais e internacionais que geram uma sociedade "de recuo à teoria" e de "marcha-ré intelectual". Neste processo o ideário "saber fazer", presente na utopia praticista da sociedade contemporânea, é ilusoriamente suficiente para resolver os problemas sociais, porém justifica a experiência imediata e a prática reflexiva pautada no empirismo e não no conhecimento.

\section{Considerações Finass}

Ao investigar a apropriação dos conceitos de Vigotski em trabalhos científicos publicados na área da educação física, desde o ano de 1990 até 2007, percebemos que ainda temos muito a avançar, no sentido de potencializar estudos acadêmicos de maior rigor epistemológico. 
É com a visão desse contexto, no qual está inserida a escola, que a educação, e também a educação física, devem materializar suas pesquisas, buscando superar os discursos pragmáticos, avançar para um aprofundamento teórico e negar produções superficiais, desprovidas de reflexões que revelem contradições sociais. Os reflexos deste exercício dialético poderão ser observados paulatinamente, contudo trarão os efeitos esperados pela sociedade no que diz respeito às possibilidades educacionais.

Tentamos nesse estudo tratar de forma especial conceitos que representam o legado vigotskiano. Para isso, tentamos ir além das superficialidades e não ignoramos o desejo de Vigotski, de formar um novo homem a partir da transformação das relações sociais e de trabalho, caracterizando os estudos que dedicou ao longo de sua vida na compreensão da psique humana.

Com este trabalho defendemos que uma mudança na área da educação física possa ser visualizada, a partir do trato minucioso com a teoria que caminhe na direção do retorno às produções e pesquisas mais aprofundadas na área, o que pode se constituir nos primeiros passos para uma transformação real, racional e radical. 


\section{Appropriation of the Lev Semenovitch Vygotsky's concepts in the Physical Education area}

Abstract: Investigated how was the appropriation of Vygotsky's concepts in scientific papers published in the area of physical education, between the years 1990 to 2007 in order to ascertain which concepts were used and how they were incorporated. Selected for the study three magazines in the area: Brazilian Journal of Sports Science, Movement Journal and Journal of Physical Education/UEM. This research was characterized as the bibliographical and analytical methods used was the historical and dialectical materialism. The results indicate that progress is needed in studies of Vygotsky, in order to enhance academic research more rigorous epistemological.

Keywords: Historic-Cultural Psychology.

Epistemology. Research. Physical Education.

Apropiación de conceptos del Lev Semenovitch
Vygotsky en el ámbito de la investigación en
Educación Física
Resumen: Investiga cómo era la apropiación de los
conceptos de Vygotsky en artículos científicos
publicados en el campo de la educación física, entre
los años 1990 a 2007 a fin de determinar qué
conceptos se utilizaron y cómo se han admitido.
Seleccionados para el estudio, tres revistas en el área:
Revista Brasileña de Ciencias del Deporte, Revista
Movimiento y Revista de la Educación Física/UEM. El
trabajo se caracterizó como los métodos bibliográficos
y de análisis utilizados fueron el materialismo histórico
y dialéctico. Los resultados indican que es necesario
avanzar en los estudios de Vygotsky, con el fin de
mejorar la investigación académica más rigurosa
epistemológico.

Palabras clave: Psicología Histórico-Cultural. Epistemología. Investigación. Educación Física. 


\section{REFERÊNCIAS}

CASTRO JÚNIOR, L. V.; SANT'ANNA SOBRINHO, J. O ensino da capoeira Nagô: por uma prática Nagô. Revista Brasileira de Ciências do Esporte, Campinas, v. 23, n. 2, p. 89-103, jan. 2002.

DUARTE, N. A Escola de VIGOTSKI e a Educação Escolar: algumas hipóteses para uma leitura pedagógica da psicologia Histórico-Cultural. Araraquara, 1995. Disponível em: <http://www.geocities.com/Athens/lthaca/3745/odonto/ VIGOTSKY.htm>. Acesso em: 31 de mar. 2009.

DUARTE, N. Vigotski e o "aprender a aprender": crítica às apropriações neoliberais e pós-modernas da teoria vigotskiana. 2. ed. rev. e ampl. Campinas: Autores Associados, 2001.

FACCI, Marilda Gonçalves Dias. Valorização ou esvaziamento do trabalho do professor?: um estudo crítico-comparativo da teoria do professor reflexivo, do construtivismo e da psicologia vigotskiana. Campinas, SP; Autores Associados, 2004.

FALKENBACH, A. P. A inclusão de crianças com síndrome de down na psicomotricidade relacional: um estudo de caso. Revista da Educação Física/ UEM, Maringá, v. 14, n. 2, p. 113-122, 2. sem. 2003.

FALKENBACH, A. P.; DREXSLER, G.; WERLE, V. Didática da educação física e inclusão. Revista Brasileira de Ciências do Esporte, Campinas, v. 28, n. 2, p. 103-119, jan. 2007.

GOELLNER, S. V. A categoria da atividade e suas implicações no desenvolvimento humano. Revista Brasileira de Ciências do Esporte, Campinas, v. 13, n. 2, p. 288-292, jan. 1992.

MORAES, Maria Célia Marcondes. Recuo da teoria: dilemas na pesquisa em educação. In: REUNIÃO ANUAL DA ANPEd, 24., 2001, Caxambu. Anais... Caxambu: ANPEd, 2001. Disponível em: <http://www.anped.org.br/reunioes/24/ T1722216449491.DOC>. Acesso em: 20 mai. 2003.

MOVIMENTO, Revista da Escola de Educação Física da UFRGS, Porto Alegre, RS, 1994-2007. ISSN: 0104-754X.

REVISTA BRASILEIRA DE CIÊNCIAS DO ESPORTE. Campinas: Colégio Brasileiro de Ciências do Esporte, 1990-2007. ISSN: 0101-3289

REVISTA DA EDUCAÇÃo FísıCA, Universidade Estadual de Maringa, Mringá, PR, 1990-2007. ISSN: 0103-3948

ROMA, C. G. et al. A avaliação psicológica na escola e a teoria histórico-cultural: Difusão nos periódicos de psicologia. Encontro: Revista de Psicologia, Santo André, v. 11, n. 15, p. 85-100, Jan./Jun. 2007. 
SAVIANI, D. Educação: do senso comum à consciência filosófica. 15. ed. Campinas: Autores Associados, 2004.

SILVA, F. G. da. Os conceitos de Vigotski no Brasil: uma análise da produção divulgada nos cadernos de pesquisa. Dissertação (Mestrado em Psicologia da educação). Pontifícia Universidade Católica de São Paulo, PUC/SP, 2003.

TRUJILLO FERRARI, A. Metodologia da pesquisa científica. São Paulo: McGraw-Hill do Brasil, 1982.

TULESKI, S. C. Vygotski: a construção de uma psicologia marxista. Maringá: Eduem, 2002.

TULESKI, S. C. Vygotski: a construção de uma psicologia marxista. 2. ed. Maringá: Eduem, 2008.

VYGOTSKY, L. S. Problemas teóricos y metodológicos de la psicologia. Madrid: Visor, 1991. (Obras escogidas, 1).

Endereço para correspondência:

leda Parra Barbosa-Rinaldi

Rua Argentino Moreschi, 396, Jardim Moreschi

Cep. 87080-127

Maringá-Paraná.

Recebido em: 6.11.2010

Aprovado em: 18.07.2011

Movimento, Porto Alegre, v. 17, n. 02, p. 75-91, abr/jun de 2011. 
